\title{
THE IMPLICATIONS OF E-COMMERCE FOR SOFTWARE PROJECT RISK: A PRELIMINARY INVESTIGATION.
}

\author{
KENNETH J. STEVENS ${ }^{1}$ and GREG T. TIMBRELL ${ }^{2}$ \\ ${ }^{I}$ School of Information Systems, Technology and Management, University of New South \\ Wales, Australia \\ ${ }^{2}$ Information Systems Management Research Group, Queensland University of Technology, \\ Australia
}

Abstract: When a business introduces the use of e-commerce applications the software related business risks the business faces change. A corresponding change may also occur in the risks faced by the developers of the e-commerce applications. Unrecognised changes in the risks involved in software projects have considerable implications for a business. This paper reports the outcomes of the preliminary phase of a study into the implications of e-commerce for software project risk in financial institutions. Firstly, the analysis draws on the e-commerce and systems development literatures to determine the differences between e-commerce development projects and traditional development projects. Four key areas of difference were found between traditional projects and e-commerce including changes in the development process outcomes, changes in the development processes and methods, changes in stakeholder groups and changes in determining application requirements. Secondly, the differences are analysed against a set of software project risk factors from a recent reputable study. Each of the risk factors was affected in some way. Some of these impacts appear to be temporary, while others appear highly dependent upon the individual circumstances of the organization undertaking the project. Some risks did, however, appear to be permanently increased or decreased, thus signalling a fundamental difference in the overall risk profile of e-commerce projects when compared to traditional projects. Whether the impacts are temporary, contextual or permanent, they all have implications for way in which risk in e-commerce software projects is assessed and managed.

The original version of this chapter was revised: The copyright line was incorrect. This has been corrected. The Erratum to this chapter is available at DOI: 10.1007/978-0-387-35692-1_36 


\section{INTRODUCTION}

The introduction of internally developed e-commerce applications had challenged traditional notions of software development within information technology divisions (Earl \& Khan, 2001). E-commerce software application stakeholder groups have broadened considerably; requirements definitions cannot be solicited as easily; timeframes have shortened; and methodologies for e-commerce application development have yet to reach the maturity of traditional software development projects. A consequence of these developments is a change in the software project risk profiles of e-commerce application development.

This paper describes the initial phase of a study of e-commerce software project risk, being undertaken in the finance industry in Australia through the Security Industry Research Centre of Asia Pacific (SIRCA). The unit of analysis of the study is the software project and the main research question is "what are the risks facing e-commerce software projects, and how are they best managed?" The planned research involves case studies of e-commerce application development projects in a number of leading financial institutions. Financial institutions are of particular interest because of their reliance on credible and reliable performance of secure transactions, which makes them particularly sensitive to risks regarding the systems that process the transactions. Many of these systems support e-commerce or are linked to e-commerce applications. These systems also underpin the e-commerce systems of many other businesses. The outcomes of this study will be not only relevant to the finance industry, but also to their customers and partners in providing online commercial activities.

Before the empirical phase of the study can commence, an understanding of how software project risk differs between traditional software projects and e-commerce software projects needs to be developed, so that the research can be properly focused. This paper presents an initial analysis, based on the literature, of the possible impact of the differences between e-commerce projects and traditional process on software project risk. Firstly, the paper provides a background to software project risk. Following this is analysis of the recent literature that distils the differences between traditional software projects and e-commerce software projects. The impact of these differences on software project risk factors is then analysed and discussed. Finally, the paper provides conclusions, outlines the limitations of the analysis undertaken and discusses the implications of the findings on the anticipated study.

This paper provides an insight into differences in software project risks between traditional and e-commerce software projects and should be of 

preliminary investigation.

interest to those engaged in the research or practice of software project risk management.

\section{BACKGROUND}

E-commerce is variously defined in literature. For the purposes of this study the definition adopted is a 'broad usage that includes all business that takes place between a business and its customers or a business and other business that is electronically mediated via the Internet'. E-commerce applications (or information systems) are those software applications that facilitate these exchanges ${ }^{10}$.

E-commerce has become one of the major factors that will determine the future survival or success of organizations and is seen by many to signify a fundamental shift in the way in which organizations operate, interact and compete (Holsapple \& Singh, 2000). Incorporated within this shift are changes in the risks that businesses engaged in e-commerce face. Freeman (2000) notes "Internet risk becomes an increasingly significant component of business's operational risk" and O'Neil (2000) notes "typical business risks, such as loss of revenue, business interruption, fraud and loss of reputation, are magnified for businesses engaged in e-commerce". Other ecommerce related risks identified in the literature include liability for content, reputation and security (Jorgensen, 1988), extortion, business interruption, third party liability (Ceniceros, 2000), technical threats to content, legal and commercial risks, denial of service attacks (Wright, 2001) and customer-expectations risk, reputation risk, security risk (McNamee \& Chan, 2001). These risks are the business risks that arise though the use of ecommerce applications and are considered to be software risks.

As the risks faced by business' change when e-commerce applications are brought into operation, corresponding changes may also occur in the risks faced by the developers of e-commerce applications. Unrecognised changes in each of these risks could have far-reaching implications for business and project alike. It appears that researchers and professional groups are beginning to recognise nature of software risk attributable to ecommerce, however little work has been undertaken into the software project risk faced by e-commerce projects. Yan and Paradi (1999) found that the characteristics of e-commerce success in these institutions include a need

${ }^{10}$ This definition does not include software / hardware that form part of the communications infrastructure and is in line with the distinction that is made between a traditional application and the operating system. 
for a high tolerance to risk and a capacity to deal with the risks, suggesting understanding e-commerce related risks is fundamental to the success ecommerce systems and a worthwhile research pursuit.

\subsection{Software Project Risk}

One consistent factor influencing project success is the various risks associated with developing projects (Jiang \& Klein, 2001). Experience has shown that risk management must be of critical concern to the project managers, as unmanaged or unmitigated risks are one of the primary causes of project failure (Royer, 2000). The high failure rate of software projects is often attributed to managers not taking prudent measures to assess and manage the risk involved in projects (Keil, Cule, Lyytinen \& Schmidt, 1998), however, risk assessment and management in regard to software projects, is something that is done minimally, if at all (Smith, McKeen \& Staples, 2001).

Schmidt, Lyytinen, Keil \& Cule, (2001) define software project risk as the product of uncertainty associated with project risk factors and the magnitude of potential loss due to project failure, where a risk factor is defined as a condition that can present a serious threat to the successful completion of a software development project. Software project risk management is the assessment and management of those risk factors that are present or arise during the software development project. The scope of software project risk is limited to the software development project only, and only those factors that can impact on the outcomes of the development process are considered. This constraint distinguishes software project risk from the broader concept of software risk ${ }^{11}$. Organizational impacts and the business risks that may arise from the subsequent use of a software application are considered "down stream" of the software project risk.

Software development risk, as defined by Barki, Rivard \& Talbot, (1993) and in the software engineering literature (such as Gluch, 1994), is incorporated within this definition of software project risk, as it is seen as slightly narrower construct.

Appropriate risk assessment and management methods in regard to these risks have been found to improve the overall handling of the software

${ }^{11}$ Software risk is variously defined in the information systems and software engineering literature. Definitions range from a very board notion that incorporates all risks that can be related to the use of software within the organization (including development projects), such as Sherer, 1995, and Longstaff, Chittister, Pethia \& Haimes, 2000, and to some extent Higuera \& Haimes, 1996. It is also defined very narrowly and similar in meaning to the use of software project risk in this paper, as in Ropponen \& Lyytinen, 1997. In this paper the software risk is used its broad sense. 

preliminary investigation.

development related risks (Ropponen \& Lyytinen, 1997) and hence improve the likelihood of project success, or at least assist to guard against it's failure.

\subsection{Software Project Risk Factors}

Software project risk factors are the 'sources' of risk to a software project. They are those factors that can have a detrimental impact upon one or more of the success criteria of a project, such that they cause the project to run over time, cost more than anticipated or result in the application not having the functionality or usefulness required. The factors that apply to a specific project are seen to constitute that project's risk profile.

Numerous lists and taxonomies of risk factors exist (Barki et al., 1993, Boehm, 1991, Sherer, 1995, Moynihan, 1997, Ropponen \& Lyytinen, 2001). A recent empirical study (Keil et al., 1998, Schmidt et al., 2001) undertook a Delphi study of project managers in Finland, Hong Kong and the U.S.A. to determine a ranked list of current risk factors. The "top 11" of these factors, as presented in Keil et al., (1998) are given in the table below:

\begin{tabular}{|l|l|}
\hline Rank & Risk Factor \\
\hline 1 & Lack of top management commitment to the project \\
\hline 2 & Failure to gain user commitment to the project \\
\hline 3 & Misunderstanding of requirements by the developers \\
\hline 4 & Lack of adequate user involvement in the project \\
\hline 5 & $\begin{array}{l}\text { Failure to manage end user expectations in regard to the } \\
\text { projects outcomes }\end{array}$ \\
\hline 6 & Changing scope and / or the objectives of the project \\
\hline 7 & $\begin{array}{l}\text { Lack of required knowledge / skills in the project } \\
\text { personnel }\end{array}$ \\
\hline 8 & $\begin{array}{l}\text { Lack of frozen requirements, such that the requirements } \\
\text { continue to change throughout the development project }\end{array}$ \\
\hline 9 & Introduction of new technology \\
\hline 10 & Insufficient / inappropriate staffing \\
\hline 11 & Conflict between user departments \\
\hline
\end{tabular}

Table 1. Top 11 Software Project Risk Factors (Keil et al., 1998)

The Keil et al., (1998) study did not appear to have captured these risk factors in regard to any particular type or class of application, so these factors considered generic' and applicable to systems development in general. It is assumed that these factors represent traditional software developments, given their similarity to other findings (Barki et al., 1993). Any substantial differences between e-commerce development projects and traditional development projects may change the relative importance or 
applicability of these risk factors. The following section seeks to determine the differences between e-commerce development projects and traditional development projects and then analyse the impact of those differences on software project risks.

\section{ANALYSIS AND RESULTS}

The analysis involves two steps. Firstly, the differences between ecommerce development projects and traditional development projects are considered and; secondly, these differences are analysed against a set of software project risk factors.

\subsection{E-Commerce Project Differences}

Like any systems development, the development of e-commerce applications is a complex task (Standing, 2002), however, there is evidence to suggest that the e-commerce development process is different from what has come before. Earl \& Khan (2001), in a study of an e-commerce specific IT department, found a variety of new practices and procedures particular to e-commerce were evolving.

To understand better the general nature of these evolving differences, a review of the e-commerce and systems development literature was undertaken. The analysis considered each phase of the development process, the approaches to development, development tools used, and project management practices.

\begin{tabular}{|l|l|}
\hline Areas of Change & Noted Key Differences \\
\hline Development outcomes & Applications built with an expectation of a short life \\
\hline $\begin{array}{l}\text { Development processes, } \\
\text { methods and techniques }\end{array}$ & $\begin{array}{l}\text { Less structured methods } \\
\text { More iterative / evolutionary techniques } \\
\text { Modularised development } \\
\text { Development timeframe is significantly shorter }\end{array}$ \\
\hline Stakeholders & $\begin{array}{l}\text { Much broader stakeholder groups } \\
\text { Multiple internal user groups } \\
\text { Multiple external user groups } \\
\text { Greater diversity in computer skills, domain knowledge, } \\
\\
\text { culture and language. }\end{array}$ \\
\hline Scope and Requirements & $\begin{array}{l}\text { Considerably more volatile } \\
\text { Multiple reference groups }\end{array}$ \\
\hline
\end{tabular}

Table 2. Key Differences Between Traditional and E-Commerce Development Projects 
preliminary investigation.

The differences found have been grouped into four categories. These categories 'emerged' from the analysis and are not meant to be mutually exclusive. A summary of the key differences is set out in Table 2 and discussed at length below.

\subsubsection{Changes in development outcomes}

The significant costs of traditional systems development efforts typically necessitate the long-term use of an application to achieve an acceptable return on investment. Many of the current development practices are geared towards generating systems that are sufficiently robust and flexible to allow long effective lives.

E-commerce development, however, appears to be different. Earl \& Khan, (2001) found a shift in development ethos from "built to last" to "launch and learn", resulting smaller systems that are considered disposable. Standing (2002) maintains that the entire notion of project completion is now inappropriate because of the need to constantly modified and update systems. The new goal in the development process appears to be 'time to market', as reflected in shorter development timeframes and the new outcomes of the development process are small, highly modularised, components that are added, used, then redeveloped or scraped as required.

\subsubsection{Changes in development processes, methods and techniques}

Standing (2002) states "the popular assumption is that processes, methods and techniques used for applications developments have changed radically as the focus of applications has moved from the traditional information systems domain to the Web". These changes include:

Firstly, a change in the development ethos to "more like craft than engineering" approach which involves "much learning by doing and a sense of being free from rules" (Earl \& Khan, 2001).

Secondly, few traditional methodologies are considered appropriate for the development of e-commerce applications (Standing, 2002). Earl \& Khan (2001) also found a move from the traditional waterfall method to a "newventure" style of development because the waterfall method was considered too linear, too long, lacking in appeal to creative designers and could not cope with continuous change. The issue of the linearity within the development cycle is also address by Gordijn, Akkermans \& van Vliet, (2000) who found "design decisions about e-business models and the associated information systems architecture cannot be sequentially made in a decoupled way, because business and technology considerations are strongly 
linked". Gordijn et al., (2000) also note the inadequacy of current methodologies because of their focus on discovering requirements rather than creating requirements. A number of studies offer alternative development methodologies for e-commerce and web development. $\mathrm{Li}$, Chen \& Chen, (2000) and Howcroft \& Carroll, (2000) propose novel ways to undertake e-commerce developments, which are quite dissimilar to traditional application development methods.

Thirdly, the composition of the development teams appears to have changed. Earl \& Khan (2001) note the need for multi-disciplinary teams that include users, technical types and creative types. Standing (2002) likens the e-commerce development team to that of a film production team.

Finally, the timeframe in which e-commerce applications are developed appears to be somewhat shorter than that allowed for more traditional projects. Earl \& Khan (2001) report that some respondents in their study indicated that projects would only be undertaken in they could be completed in less than three months. Hammar-Cloyd, (2001) notes that many ecommerce developers are "under pressure to develop new applications faster" and $\mathrm{Li}$ et al., (2000) found faster revision cycles have lead to a blurring of development and maintenance phases.

\subsubsection{Changes in stakeholder groups}

A number of key differences the nature of stakeholders in e-commerce development and traditional development exist.

Firstly, the number of stakeholder groups involved in a development project has increased dramatically. Standing, (2002) notes that many webbased system are multi-functional, requiring user representatives from throughout the organization. Users external to the business, in the form of customers, suppliers and so on, are also now included in the stakeholder group. . This broadening of the stakeholder group has implications for the development of e-commerce systems including the funding, the potential for conflict between the user groups in regard to the systems requirements, the need to integrate the e-commerce system with multiple internal systems, the acceptance of the developed system and the management of its ongoing evolution and maintenance.

Secondly, the expanded user base is considerably more diverse. As the internal user groups are identifiable, assumptions to be made about their computer competency, business knowledge, language and culture. It is difficult to see how these assumptions could be made about the external users, as considerable diversity would exist in each of the above areas, thus posing considerable implications for the requirements of an e-commerce system. 

preliminary investigation.

\subsubsection{Changes in requirements}

A number of clear differences exist in the determination of the requirements for an e-commerce application and a more traditional application.

Firstly, the elicitation of requirements is seen as problematic as the requirements may simply not exist. Eliciting requirements is dependent upon users understanding the needs of the underlying business activities. In the case of e-commerce, where the system is good proportion of the underlying activities, the requirements many have to be created from scratch rather than discovered (Gordijn et al., 2000).

Secondly, the requirements will need to be elicited from the broader user base. Such diverse reference groups are bound to increase requirements conflict between stakeholder groups. The lack of underlying business models would tend to exacerbate these conflicts (Gordijn et al., 2000). The articulation of the requirements in regard to the new external user group is also problematic in terms of who actually articulates them.

Thirdly, the potential diversity of the external user base creates a considerably expanded set of requirements to accommodate different skill and knowledge levels, different languages, different data formats and conventions (Hasselbring, 2002), integration with both internal and external legacy systems and so on. These differences have implications not only for the main functionality, presentation and data of the system but also for ancillary functions such as online help.

Finally, it is apparent that the requirements for e-commerce systems are far less stable than other systems. The relative newness of the systems, the incremental nature of the development approach, the rapid evolution of the underlying technology and the competitive pressure from business units all seem to create a situation in which the requirements are in almost constant flux (Earl \& Khan, 2001).

\subsection{Impact of project differences on software project risk}

In the above analysis, several key differences were noted between the ecommerce and traditional development projects. To gain an understanding of how these differences translate to a change in the risk profile of an ecommerce software project, an analysis of a common set of software project 
risk factors against these changes was required. The set of risk factors used in the analysis are from Keil et al., (1998) ${ }^{12}$

The analysis involved considering each risk factor in light of the differences between e-commerce and traditional software projects. The impact of each difference was considered in light of three perspectives: the direction of change in the factor; the permanence of the impact on the factor; and effect of context on of impact, as discussed below.

\subsubsection{The direction of change in the factor}

Each factor was considered in the light of each difference as to the extent to which the difference would cause change in the operation of that factor:

- Decrease - in that the operation of the factor would be diminished, hence contributing to a reduction in the project risk.

- Little or no change - in that the operation of the risk factor would remain more or less unchanged.

- Increase - in that the operation of the factor would be exacerbated, hence contributing to an increase in the project risk.

A simple three-point scale (increase, decrease or little or no change) has been used to categorize the direction of the change to keep the analysis simple.

\subsubsection{The permanence of the impact on the factor}

Each factor was also considered in regard to the permanence of the impact. The distinction between temporary and permanent effects appeared important as in terms of how the changes in the risk might be managed and how it might change over time.

\subsubsection{The extent of context of impact on the factor}

The impact of each factor was also considered in regard to the extent to which variation in the risk factor would be more attributable to the individual circumstances of an organization rather than in response to the fact that development was an e-commerce development. This perspective

${ }^{12}$ Keil et al., (1998) undertake a Delphi study of software development project managers from the USA, Hong Kong and Finland, providing strong validity. The study is also relatively recent, but no so recent as to already include the effects (if any) of e-commerce development. 
preliminary investigation.

was important as it accommodates situations where credible arguments could be mounted for change in the risk factor either way.

\subsection{Results of analysis of the impact of development differences on risk}

The analysis of four areas of difference (as set out in table two) against the eleven risk factors (as set out in table one) across the three perspectives discussion above resulted in a large and interesting data set. A summary of the analysis is set out in the following table.

In the table, the column "Risk Factor" lists each of the risk factors from Keil et al., (1988). The factors are ranked in order of importance, as per the study. The column "Expected change in factor" provides an estimation of the change in each risk factor in terms in light of the aggregated effect of all of the differences between e-commerce projects and traditional projects. Where this change is considered temporary or highly contextual, then this is also noted.

\begin{tabular}{|c|c|c|}
\hline & Risk factor & Expected change in factor \\
\hline 1 & $\begin{array}{l}\text { Lack of top management commitment to the } \\
\text { project }\end{array}$ & $\begin{array}{l}\text { Little or no change as highly } \\
\text { contextual }\end{array}$ \\
\hline 2 & $\begin{array}{l}\text { Failure to gain user commitment to the } \\
\text { project }\end{array}$ & Decrease \\
\hline 3 & $\begin{array}{l}\text { Misunderstanding of requirements by the } \\
\text { developers }\end{array}$ & Increase (and temporary) \\
\hline 4 & $\begin{array}{l}\text { Lack of adequate user involvement in the } \\
\text { project }\end{array}$ & Decrease \\
\hline 5 & $\begin{array}{l}\text { Failure to manage end user expectations in } \\
\text { regard to the projects outcomes }\end{array}$ & Decrease (highly contextual) \\
\hline 6 & $\begin{array}{l}\text { Changing scope and / or the objectives of } \\
\text { the project }\end{array}$ & Increase (partially temporary) \\
\hline 7 & $\begin{array}{l}\text { Lack of required knowledge / skills in the } \\
\text { project personnel }\end{array}$ & Increase (temporary) \\
\hline 8 & $\begin{array}{l}\text { Lack of frozen requirements, such that the } \\
\text { requirements continue to change throughout } \\
\text { the development project }\end{array}$ & Increase \\
\hline 9 & Introduction of new technology & Increase (temporary) \\
\hline 10 & Insufficient / inappropriate staffing & Increase (temporary) \\
\hline 11 & Conflict between user departments & Increase \\
\hline
\end{tabular}

Table 3. Summary of Impacts on Risk Factors 


\subsection{Discussion of impact on individual risk factors}

The key points that arose of the analysis of each factor are discussed below.

\subsubsection{Lack of top management commitment to the project}

Top management support has been the "bug bear" of information systems projects for many years. The operation of this factor in regard to ecommerce is difficult to understand. On one hand, if management sees ecommerce are important to the business's future than support may be forthcoming, on the other hand, the historical precedence that makes this item the single most important risk factor in the Keil et al., (1998) study, would suggest that management will pay scant attention to e-commerce. We suggest that in this regard the impact of the factor is highly contextual, in that it will operate in different ways in different organizations influenced by factors other than the fact they the development is e-commerce.

\subsubsection{Failure to gain user commitment to the project}

We suggest this factor should decrease, as e-commerce developments appear to be more inclusive of users. Identifying the appropriate users from which to gain commitment could be difficult and may dampen any effect.

\subsubsection{Misunderstanding the requirements by the developers}

An increase in this factor is expected because of the volatility of the requirements, the increased number of stakeholders, increased conflict between stakeholder groups, and difficulties in determine "what the customer wants". It is expected that as the organization learns how to develop e-commerce systems that the propensity to misunderstand the requirements may diminish.

\subsubsection{Lack of adequate user involvement in the project}

Like Factor 2, this factor should probably decrease, as the literature is clearly pointing towards more inclusive development teams. The sheer number of differing user groups could dilute any decrease. 

preliminary investigation.

\subsubsection{Failure to manage end user expectations in regard to the project outcomes}

Like Factor 3, this factor is expected to increase because of the volatility of the requirements, the increased number of stakeholders, increased conflict between stakeholder groups, and difficulties in determine "what the customer wants". This factor is exacerbated by apparent difficulties in understanding the requirements of external users, as they are outside the business and it becomes difficult or inappropriate to determine their needs. A diverse user group will yield diverse expectations.

\subsubsection{Changing scope / objectives}

In a similar manner to Factor 2, the overall objectives of the systems may be difficult to "pin down", until the capability of the technology is well understood. In a more permanent change, the ongoing volatility of the requirement can make scope and objective decisions more difficult. The noted change in development ethos towards more short term, disposable systems, may partially ameliorate this impact.

\subsubsection{Lack of required knowledge / skills in the project personnel}

A temporary increase is expected to occur until necessary skills are obtained. The different composition of project teams could exacerbate the increase for some time.

\subsubsection{Lack of frozen requirements}

A permanent increase is expected to occur in this factor as our analysis indicates that the new hallmark of e-commerce development is the fluidity of the requirements. The shorter time frame for development would seem to act to restrict the impact on this factor, as any problems that arise from incorrect functionality could be quickly overcome within the next iteration of the development cycle.

\subsubsection{Introduction of new technology}

A temporary increase is more likely to occur until the technology is understood and absorbed into the IT infrastructure and architecture. The ongoing development and release of new technologies (web-based 
programming languages / tools, communication technologies and the like) is likely to prolong the impact on this factor.

\subsubsection{Insufficient / inappropriate staffing}

A temporary increase is expected to occur until necessary skills are obtained. The different requirements for project team composition of project team could exacerbate the increase for some time.

\subsubsection{Conflict between user departments}

We believe this factor should increase in line with the increased number of stakeholders / user groups.

\subsection{Discussion of results}

The analysis suggests that a number of definite and significant differences between e-commerce development projects and traditional development project either exist or are beginning to emerge. Numerous differences where found. Some we expect to be "temporary" or "contextual". Temporary effects were those noted differences that related the novelty of the application, rather than the fact that it is an e-commerce application being developed. Contextual effects were those noted differences that related more the circumstances of the business undertaking the development. Other, more permanent differences were also noted, where it is the nature of the ecommerce applications themselves that cause the difference. Each of these difference effects requires a different response to managing the development risks associated with that effect.

A key goal of the analysis articulated in this paper was to determine the specific hypotheses to explore using case study methods. Case study is appropriate because of its ability to explicate the rich context needed to explore the risk determinants across a diverse stakeholder group in a contemporary setting and compare these with recent developments in software development project risk generally. Case studies also seek to 'understand' (in a phenomenological or hermeneutic sense) the meaning held by a subject or group rather than 'explanation' (as produced by a scientific 'explanation') (Gable, 1994). It is proposed that data will be collected using techniques as semi-structured interviews, participant observation, and sifting project team meeting records and other relevant project artifacts to explore the hypotheses derived from the expected differences listed and summarised in table 3. 

preliminary investigation.

\section{CONCLUSIONS}

The investigation presented in this paper sought to gain an initial understanding of the differences between e-commerce software projects and traditional software projects and to analyse these differences in regard to their impact on software project risk. An analysis of the literature revealed a number of changes in the outcomes of the project, the project methods and process, the stakeholders involved and the requirements of e-commerce applications.

When these differences are analysed against a set of software project risk factors from a recent reputable study (Keil et al., 1998), each risk factor was affected in some way. Some of these impacts appeared to be temporary, while others appeared highly dependent upon the individual circumstances of the organization undertaking the project. Some risks did, however, appear to be permanently increased or decreased, thus signalling a fundamental difference in the overall risk profile of e-commerce projects when compared to traditional projects. Whether the impacts are temporary, contextual or permanent, they all have implications for way in which risk in e-commerce software projects is assessed and managed.

\subsection{Limitations}

The paper suffers from a number of limitations. Firstly, the paper only seeks to examine the impact of the development differences in respect of known risk factors and, as such, ignores the possibility of identifying factors unique to e-commerce. Secondly, the assumption that the risk factors used relate to "traditional" software development projects rather than e-commerce projects may incorrect. If the participants in the Keil et al., (1998) study (from which the risk factors are drawn) did consider e-commerce projects in their responses then the analysis in this paper may indeed be double counting the impact of e-commerce development on risk factors. Thirdly, e-commerce projects and traditional projects have been used in a generic sense, without regard to the actual considerable variation in applications within these two categories. It has been assumed that risk factors would apply equally to all to e-commerce applications and this may not be the case. Subsequent phases of this research will need to address each of these limitations, however, given the preliminary nature of the initial phase of the research reported in this paper, the limitations do not detract significantly from the overall conclusions. 


\subsection{Implications to project managers and researchers}

The analysis in this preliminary study proposes two ideas. Firstly, there is a marked difference between e-commerce software projects and traditional software projects and secondly, these differences have material implications for the risk factors of software project risk.

The key implication of these differences for project managers is the need to reassess their understanding of the risks they face when undertaking ecommerce projects and reassess the techniques that they use to manage and mitigate those risks. Project managers also need to ensure that their risk assessment mechanisms allow them to look beyond the usual risks.

The key implication for these findings for researcher it the need to undertake further work to better determine the nature of the differences in ecommerce and traditional projects, the subsequent impact on software project risks factors, and the way in which the risks may be best managed. In regard the proposed research study outlined at the beginning of this paper, the outcomes of initial analysis presented above provides more than adequate grounds to proceed to the next phase of the proposed research.

\section{REFERENCES}

Barki, H., S. Rivard, J Talbot (1993), 'Toward an Assessment of Software Development Risk', Journal of Management Information Systems 10(2), 203-225.

Boehm, B.W. (1991), 'Software Risk Management: Principles and Practices', IEEE Software 8(1), 32-41.

Ceniceros, R. (2000), 'Managing e-commerce risks', Business Insurance 34(4), 29.

Gable G. (1994), 'Integrating case study and survey research methods: an example in information systems', European Journal of Information Systems, 3(2), 112-126.

Hammar-Cloyd, M. H. (2001), 'Designing User-Centered Web Application in Web Time', IEEE Software 18(1), 62-69.

Earl, M. and B. Khan (2001), 'E-Commerce is Changing the Face of IT', MIT Sloan Management Review 43(1), 64-72.

Freeman, E. Q. (2000), 'E-Merging Risks: Operational Issues and Solutions in a Cyberage', Risk Management 47(7), 12-16.

Gable, G. (1994), 'Integrating case study and survey research methods: an example in information systems', European Journal of Information Systems 3(2), 112-126.

Gordijn, J., H. Akkermans, H. van Vliet (2000), 'Value Based Requirements Creation for Electronic Commerce Applications', in 'Proceedings of the $33^{\text {rd }}$ Hawaii International Conference on Systems Sciences', Hawaii, Jan 4-7, pp. 1915 -1924.

Gluch, D. P. (1994), 'A Construct for Describing Software Development Risks', Technical Report CMU/SEI-94-TR-14, Software Engineering Institute, Carnegie Mellon University.

Hasselbring, W. (2002), 'Web Data Integration for E-Commerce Applications', IEEE Multimedia 9(1), 16-25. 
Higuera, R. P. and Y. Y. Haimes (1996), 'Software Risk Management', Technical Report CMU/SEI-96-TR-012, Software Engineering Institute, Carnegie Mellon University.

Holsapple, C. W. and M. Singh (2000), 'Electronic Commerce: From a Definitional Taxonomy Toward a Knowledge-Management View', Journal of Organizational Computing and Electronic Commerce 10(3), 149-170.

Howcroft, D. and A. Carroll (2000), 'A proposed methodology for web development' in 'Proceedings of the $8^{\text {th }}$ European Conference on Information Systems', Vienna, July 3-5

Jiang, J. J. and G. Klein (2001), 'Software Project Risks and Development Focus', Project Management Journal 32(1), 4-9.

Jorgensen, L. (1998), 'Connection to Risk? Managing the exposures of cyberspace', Risk Management 45(2), 14.

Keil, M., P. E. Cule, Kalle Lyytinen and Roy Schmidt (1998), 'A Framework for Identifying Software Project Risks', Communications of the ACM 41(11), 76-83.

Longstaff, T. A., C. Chittister, R. Pethia and Y.Y Haimes (2000), 'Are we forgetting the risks of information technology?' Computer 33(12), 43-51.

McNamee, D. and S. Chan (2001), 'Understanding E-commerce Risk', Internal Auditor 58(5), 60-61.

Moynihan, T. (1997), 'How Experienced Project Managers Assess Risk', IEEE Software 14(3), 35- 41 .

O'Neill, D. T. (2000), 'Evaluating banks' e-commerce risks', American Agent and Broker 72(11), 36-46.

Ropponen, J. and K. Lyytinen (1997), 'Can software risk management improve systems development: an exploratory study', European Journal of Information Systems 6(1), 4150.

Ropponen, J. and K. Lyytinen (2001), 'Components of Software Development Risk: How to Address Them? A Project Manager Survey', IEEE Transactions on Software Engineering 26(2), 98-112

Royer, P. S. (2000), 'Risk Management: The Undiscovered Dimension of Project Management', Project Management Journal 31(1), 6-13.

Schmidt, R., K. Lyytinen, M. Keil, and P. E. Cule (2001), 'Identifying software project risks: An international Delphi study', Journal of Management Information Systems 17(4), 5-36.

Sherer, S. (1995), 'The Three dimensions of Software Risk: Technical, Organizational and Environmental', in 'The Proceedings of the $28^{\text {th }}$ Annual Hawaii International Conference on Systems Science', Hawaii, January 3-6, pp. 369-378.

Smith, H. A., J. D. McKeen and Sandy D. Staples (2001), 'Risk Management in Information Systems: Problems and Potentials', Communications of the Association for Information Systems 7(1).

Standing, Craig (2002), 'Methodologies for developing Web applications', Information and Software Technology 44(3), 151-159.

Wright, A. (2001), 'Controlling Risks of E-Commerce Content', Computers and Security $20(2), 147-154$.

Yan, G., and J.C. Paradi (1999), 'Success Criteria for Financial Institutions in Electronic Commerce', in 'The Proceedings of the $32^{\text {nd }}$ Annual Hawaii International Conference on Systems Science', Hawaii, January 5-8, pp. 341-348. 